\title{
BMJ Open Using facilitator-receiver peer dyads matched according to socioeconomic status to promote behaviour change in overweight adolescents: a feasibility study
}

To cite: Saez L, Legrand K, Alleyrat C, et al. Using facilitator-receiver peer dyads matched according to socioeconomic status to promote behaviour change in overweight adolescents: a feasibility study. BMJ Open 2018;8:e019731. doi:10.1136/ bmjopen-2017-019731

- Prepublication history and additional material for this paper are available online. To view these files, please visit the journal online (http://dx.doi. org/10.1136/bmjopen-2017019731).

Received 22 September 2017 Revised 7 February 2018 Accepted 16 April 2018

Check for updates

${ }^{1}$ University of Lorraine, APEMAC EA 4360, Nancy, France ${ }^{2}$ INSERM, CIC-1433, CHRU Nancy, F-54 000, Nancy, France ${ }^{3}$ National Conservatory of Arts and Crafts (CNAM), Nancy,

France

${ }^{4}$ University of Lorraine APEMAC EA 4360, Metz, France

${ }^{5}$ Academy Rector of Nancy and Metz, Nancy, France

Correspondence to

Laura Saez;

laura.saez@univ-lorraine.fr

\section{ABSTRACT}

Objective To evaluate the feasibility of an innovative peer intervention promoting healthy eating and physical activity, which purposefully selected peer facilitators according to socioeconomic status to target less-advantaged overweight receivers.

Setting Nine high schools, two middle schools. Participants One hundred and fifty-six adolescents were approached to become facilitators, of whom 18 were trained. Thirty-two of 56 potential receivers agreed to participate.

Intervention The peer intervention was carried out in 2013-2014 and embedded in a larger trial: PRALIMAP-INĖS (Promotion de I'ALIMentation et I'Activité Physique-INEgalité de Santé). Facilitanoators were selected and trained to organise weight-control activities with specific peer receivers participating in the programme.

Primary and secondary outcome measures Different types of data were collected to assess demand, acceptability, implementation and practicality of the intervention. For the facilitators, this included 6 training sessions, 11 mid-programme interviews, 4 end-of-programme sessions, telephone notes and text message exchanges. All six potential receivers in one school were also interviewed. Sociodemographic and health characteristics were also analysed.

Results Agreeing to participate was more likely when asked by a peer compared with a professional $(51.2 \%$ discordant pairs; $p<0.02$ ). Twelve activities, mostly based on physical activity and implemented during weekends or holidays, were carried out. The mean age of active receivers was 16 and their body mass index was higher than other participants. For both facilitators and active receivers, there were more participating girls. Qualitative analysis reveals key implementation challenges for facilitators. Interviews with the receivers highlight social difficulties, with most feeling bad about their appearance and wanting to lose weight. Those who participated in peer activities were very positive about the experience especially social support.
Strengths and limitations of this study

To the authors' knowledge this is the first intervention to purposefully select peer facilitators matched on the basis of the socioeconomic status of the receivers.

- The peer intervention was based on sociocognitive theory with a particular focus on peer modelling, peer support and practice opportunities for mastering desired behaviours, as opposed to the traditional concept of peer education based on transmission of information.

- The intervention was embedded in a large-scale research study allowing systematic collection of data, and an indepth process analysis with different sources of qualitative materials was also carried out to triangulate findings and grasp implementation challenges.

- There were fewer peer-led activities carried out than expected, and many organisational challenges need to be addressed and serve as lessons learnt to facilitate implementation in future interventions.

- Results provide an indication of the potential feasibility of the peer intervention, but further research with a larger sample size is necessary to confirm findings on the characteristics of the participants and empirically evaluate the effectiveness of the intervention to improve the dietary and physical activity behaviours of the receivers.

Conclusions The present study suggests the peer intervention is feasible provided organisational difficulties are addressed. Good practice recommendations are formulated, including a longer training session, organising a joint meeting with the facilitators and receivers, matching dyads on place of residence and multiplying modes of contact. Trial registration number NCT01688453. 


\section{INTRODUCTION}

Schools are considered to be ideal settings for health promotion interventions, particularly in the context of lifestyle interventions for weight management. ${ }^{1-3}$ Indeed, it has been argued that the school setting intrinsically exposes children and adolescents to dietary and physical activity factors. ${ }^{4}$ Furthermore, pupils spend a significant amount of their time in school for which attendance is often compulsory. This means that it is possible for interventions to reach almost all adolescents, regardless of socioeconomic status (SES), in a relatively short time. For this reason, it has been suggested that the school setting may be particularly important in order to reduce health inequalities. ${ }^{5}$ However, concerns have been raised about the fact that school interventions may not benefit all adolescents equally and the need for specific examination of minority groups has been expressed. ${ }^{67}$

One reason that school-based interventions may not benefit all adolescents equally could be the socioeconomic gap between health experts delivering the interventions and adolescents of low SES. For example, in a French evaluation of peer-led health interventions, it was highlighted that young people are critical with regard to health prevention interventions carried out by professionals. ${ }^{6}$ It is also believed that adolescents feel stigmatised by adults because they feel they are considered as a 'risky age group', which is a negative prejudice, and they do not feel implicated in health policies designed for them. ${ }^{8}$ Furthermore, there seems to be an association between adolescents' eating habits and physical activity level and that of family and friends, suggesting involvement of adolescents' social environment may enhance the effectiveness of weight-control interventions. ${ }^{9}{ }^{10}$ For example, it has been shown that higher levels of physical activity among friends are associated with higher levels of physical activity of the individual, and that an individual's level of physical activity changes to reflect his/ her friends' higher level of physical activity. ${ }^{10}$ In addition, when health interventions are performed by peers, they seem to have a higher level of acceptability, and age proximity is especially valued because of the belief that adolescents of the same age understand each other better than adults would. ${ }^{6}$ The central tenet of the effectiveness of peer education is that the influence of peers and friends is likely to become more important as children get older. ${ }^{11}$ For example, the review by Salvy and colleagues ${ }^{11}$ highlights that young people are more physically active when in the company of peers and friends, and that overweight boys paired with non-overweight peers increase their physical activity to a level similar to the non-overweight peer.

Given these observations, a call has been made to increase the number of health promotion and prevention programmes in schools in France, especially those delivered by peers. ${ }^{6}$ Peer education has been extensively implemented with encouraging results across settings and in several health domains, especially sexual health and HIV prevention, ${ }^{12-14}$ but also smoking prevention and substance use. ${ }^{1516}$ More recently, peer-based approaches have been described as promising avenues for behavioural weight-control interventions with positive results, including weight loss, reduction in waist circumference, less sedentary behaviour, improved attitudes towards healthy eating and exercise, and increased self-efficacy. ${ }^{2}{ }^{17-24}$ Across domains, a key recommendation for school-based interventions is that they be behaviourally focused. ${ }^{7}$

Despite promising results, the evidence for the effectiveness of peer education is unclear, and one reason that has been put forward is the lack of theoretical embedding of the interventions. ${ }^{162526}$ In the present study, the choice was made to use sociocognitive theory as the theoretical basis of the intervention, ${ }^{27}$ with a particular focus on peer modelling as well as increasing self-efficacy through peer support and practice opportunities for mastering the desired behaviours. This concept of the role of peer interveners overlaps with two types of peer interventions as recently defined by Bagnall and colleagues. ${ }^{28}$ The first is peer mentoring as 'the development of a relationship between two individuals where the mentee is able to learn from the mentor, model positive behaviour and gain experience, knowledge or skills'. The second is peer support, which 'seeks to promote health and build people's resilience to different stressors'. ${ }^{28}$

The objective of this feasibility study was therefore to develop and evaluate a peer intervention to promote physical activity and healthy eating whilst intending not to widen health inequalities by purposefully selecting adolescent peer facilitators who were also of low SES in order to target less-advantaged overweight adolescents. Given the innovative method of selecting less-advantaged adolescents as peer interveners, the feasibility study aimed to assess the earlier stages of intervention development as highlighted by Bowen and colleagues ${ }^{29}$ namely intervention acceptability, demand, implementation and practicality.

\section{METHODS \\ PRALIMAP-INÈS study}

The current study was carried out during the 2013-2014 academic year within a larger research programme, PRALIMAP-INÈS (Promotion de l'ALIMentation et l'Activité Physique-INEgalité de Santé), running over a 3-year period for the prevention of overweight and obesity in France. The study protocol of PRALIMAP-INÈS has been described in detail elsewhere. ${ }^{30}$ Briefly, PRALIMAP-INÈS is a mixed quasi-experimental and experimental prospective trial aimed at overweight and obese adolescents aged 13-18 attending grade 9 in state-run middle schools (last year of 'collège' in France) and grade 10 in high schools (first year of 'lycée' in France) in the Vosges department (north-eastern France). At the beginning of the school year, a screening process was carried out in the school setting (T0). All adolescents were measured and those with a body mass index (BMI) greater than the 
International Obesity Task Force overweight thresholds for age and gender, ${ }^{31}$ or with a waist circumference greater than the McCarthy cut-off values for age and gender, ${ }^{32}$ also filled out several questionnaires and were offered a series of interventions. SES was measured using the WHO Family Affluence Scale (FAS) questionnaire, ${ }^{33} 34$ and a score equal or below 5 was considered to indicate less-advantaged status. At the end of the academic year (T1), students were measured again and filled out several questionnaires including their appreciation of the programme and its components.

\section{Peer intervention description and logic model}

As part of the PRALIMAP-INÈS programme, the current feasibility study focusing on the peer intervention was integrated and targeted at adolescents of the 'less advantaged with standard and strengthened-care' group during the 2013-2014 academic year, representing 262 adolescents. In the sense that the role of the peer interveners was to encourage physical activity and healthy eating, the term 'facilitator' was preferred and 'receivers' for those receiving the intervention.

The peer intervention was based on sociocognitive theory, which posits four mechanisms potentially important for self-efficacy and consequently the possibility of behaviour change: (1) performance outcomes, activated here by successfully carrying out weight-control activities (mastery experiences); (2) vicarious experiences, observing facilitators carry out weight-control activities; (3) verbal persuasion, facilitators should encourage healthy eating and physical activity; and (4) emotional arousal, which may in the present intervention entail positive emotions through social interaction with the facilitators during weight-control activities. ${ }^{27}$ It was expected that through mere contact with the facilitators and other peers involved in the intervention, peer receivers would benefit from general social support and develop interpersonal skills. Carrying out weight-control activities with the facilitators was expected to bring information exchange, increased self-efficacy as well as support for the target behaviour change.

To carry out the peer intervention, two types of peer facilitators were selected: peer ambassadors were adolescents having participated in the PRALIMAP-INÈS programme the previous year, and peer entrepreneurs were adolescents screened at the beginning of the school year in 2013 and having no previous experience of the programme. Both peer ambassadors and entrepreneurs were selected according to the following criteria: an ability to control their weight as evaluated by a physician, motivation to become peer facilitators and an FAS score $\leq 5$ suggesting that they were of similar socioeconomic background to the peers they would be organising activities with. In addition to similar socioeconomic background, facilitators were peers in terms of attending the same school and being close in age (the ambassadors being a year older and the entrepreneurs being from the same year group).
Peer facilitators received a 2-hour training session delivered during school time at the beginning of the academic year by a member of the PRALIMAP-INÈS team responsible for the peer intervention (LS). Training sessions were carried out in groups ranging from two to four adolescents, and if it was not possible to regroup potential facilitators, training was done on an individual basis. The first part of the training session invited each adolescent to present himself/herself and to consider why they would be a good facilitator in terms of skills and motivation. The objective of this part of the training session was to reinforce motivation and feelings of self-efficacy of the adolescents. The next part of the training session consisted of presenting the role of a facilitator and brainstorming potential activities to be carried out and resources they could call on to help them with this task. By brainstorming activities together, adolescents could be inspired from each other's ideas, get direct feedback in order to detail the implementation of their ideas with a focus on feasibility, and start understanding more concretely what their role would entail. Another key moment of the training session was role-playing key situations that the facilitators may face, including initial contact with the receivers and difficulties motivating receivers. Each role-play was followed by feedback from the participants and observers, as well as debriefing tips. Satisfaction with the training session was evaluated at the end of the session.

Following the training session, the facilitators who wished to continue were assigned a small group of peers which they had to contact and with which they were encouraged to develop activities based on their common interests to pursue throughout the academic year. The initial target was to organise and carry out four activities anytime in the school year. Great latitude was given to the facilitators as regards the choice of activities, whether they aimed at physical activity or healthy eating, as well as the time, place and implementation method of their chosen activities. The peer intervention was therefore implemented as part of a larger health programme in the school setting but designed to be non-formal in its educational approach and allow activities to be carried out outside of school premises. The facilitators discussed their chosen activities with the programme coordinator (LS), and financial support was offered if it was necessary for the implementation of the activities.

Throughout the school year, facilitators were contacted on a regular basis for follow-up and support for the implementation of the weight-control activities with their receivers in the form of telephone calls as well as text messages (SMS) by the programme coordinator (LS). A mid-programme face-to-face interview was also carried out with each of the facilitators to maintain their motivation and allow a more indepth exchange on the implementation challenges they faced. At the end of the academic year, all facilitators were invited to a formal end-of-programme session and they were rewarded for their time and effort with a certificate. 


\section{Feasibility criteria, materials and analysis}

Demand was evaluated by gathering expressed interest and participation rates in the peer intervention, for ambassadors, entrepreneurs and receivers. Expressed interest in being an ambassador, entrepreneur and receiver was obtained by a member of the PRALIMAP-INÈS team at the beginning of the school year during the screening process. The intervention was then offered a second time to the receivers directly by their allocated facilitator, which enabled a comparison of expressed interest of receivers according to whether the intervention was offered by a professional or a peer.

Acceptability of the intervention was assessed in terms of satisfaction (spontaneous expression and answers to specific questions) and perceived appropriateness (expression of unease, reluctance or, on the contrary, enthusiasm in discourse). Implementation was evaluated in terms of how many, what type and when weight-control activities were carried out, as well as assessing the type and extent of support needed from the programme coordinator in terms of number and purpose of SMS exchanges and calls. Finally, practicality was evaluated by a detailed analysis of the factors affecting implementation ease or difficulty. To answer these research questions, the training sessions, mid-programme interviews and end-of-programme sessions, on top of their functionality within the peer intervention programme, also served as focus groups. They were all audio-recorded, with the consent of the adolescents present, and transcribed. The material was then coded in NVivo V.10 by performing a thematic analysis. Telephone notes of each conversation with the facilitators and all SMS exchanges were also added to NVivo and coded. All these sources were analysed together to obtain a general view of acceptability, implementation and practicality from the point of view of the facilitators.

Furthermore, to gain more insight into the experience of the receivers, all six potential receivers from one high school, whether or not they chose to participate, were invited to an individual interview. These interviews were also transcribed, added to the NVivo database and coded using the same coding grid as the analysis on the facilitators in terms of their experience of the peer intervention, but with an additional focus on the characteristics of the potential receivers, in particular the following two themes: friendship and other peers (definition and number) and health and overweight (definition and personal experience).

A descriptive analysis was also undertaken on the information on facilitators and receivers collected by measures and questionnaires as part of the larger PRALIMAP-INÈS trial at the start and end of the school year. Physical activity and sedentary behaviour were measured by the International Physical Activity Questionnaire (IPAQ), ${ }^{35}$ the Eating Attitudes Test (EAT-26) ${ }^{36}{ }^{37}$ screened for anorexia and bulimia symptoms, the Hospital Anxiety and Depression scale (HAD) ${ }^{38}$ screened for anxiety and depression symptoms, and the Kidscreen ${ }^{39}$ explored perceived health and quality of life. Study sample characteristics (age, gender, school type, FAS, BMI) and health scores (physical activity level, total EAT-26 score, total HAD score, as well as individual scores for anxiety and depression, and the Kidscreen score) were described using percentages for categorical variables and mean \pm SD for quantitative variables. Statistical analyses were carried out using SAS V.9.4.

The main research questions to assess feasibility and how each source of data collected and analysed contributed to answering those questions are summarised in online supplementary file 1 .

The facilitator training sessions, mid-programme interviews, end-of-programme sessions, as well as the follow-up of the facilitators by phone calls and SMS exchanges were designed and carried out by the peer intervention coordinator (LS). Receiver individual interviews were designed and carried out by an MSc student (SR), in collaboration with the peer intervention coordinator. All materials were coded in NVivo by the peer intervention coordinator.

To illustrate the main qualitative results, quotes from the facilitators and receivers were selected and translated from French into English.

\section{RESULTS}

\section{Recruitment and participation}

The flow chart illustrating the recruitment process of facilitators is illustrated in figure 1. Of the 39 eligible ambassadors and 117 entrepreneurs, 20 and 36 adolescents agreed to become peer facilitators, respectively. Of the 39 facilitators who volunteered and were contacted, 18 benefited from a training session in school. The reasons for not benefiting from a training session are diverse, and include not answering, changing their mind about participating and also not having enough receivers in the school to justify training a facilitator. The 18 facilitators benefiting from a training session came from 10 different schools, and in total 6 training sessions were carried out. The participants were highly satisfied with the training session: on a 4-point scale, the average global satisfaction score with the training session was 3.8. The average scores for specific questions were 3.9 (having had a nice time), 3.8 (finding the training session useful), 3.8 (that the training session was sufficiently long), 3.7 (that it met their expectations) and 3.6 (that they felt ready to become facilitators). All scores ranged between 3 and 4 . When asked what they enjoyed most, of the 18 trained facilitators, 13 spontaneously reported the role-plays.

The recruitment process for the receivers is detailed in figure 2. Of the 151 receivers for whom there was a trained facilitator in the school who continued after training, 56 were randomly selected for contact by the facilitators. Of the 56 potential receivers, 25 did not formally accept the peer intervention, of whom only 8 actually declined to participate. Thirty-two accepted the proposition, and at the end of the peer intervention 8 adolescents had benefited from at least one weight-control activity with a facilitator. 


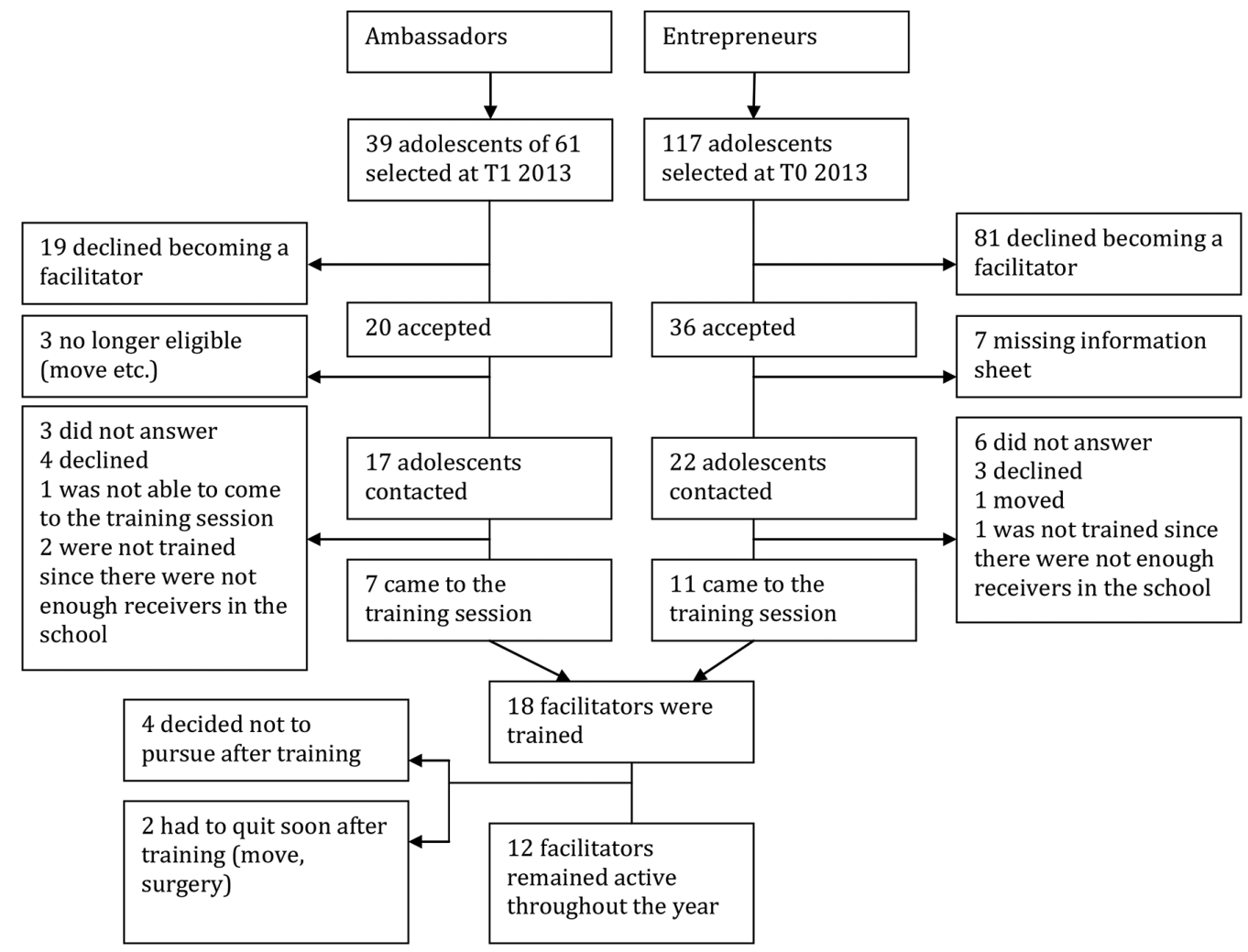

Figure 1 Recruitment process of the facilitators (ambassadors and entrepreneurs).

Twenty-four adolescents did not benefit from an activity, which in the majority of cases was due to the facilitator not managing to organise one. Another main reason for not benefiting from an activity is not being able to join for a variety of reasons, such as not having a means of transport or timetable clashes. Another interesting result is that

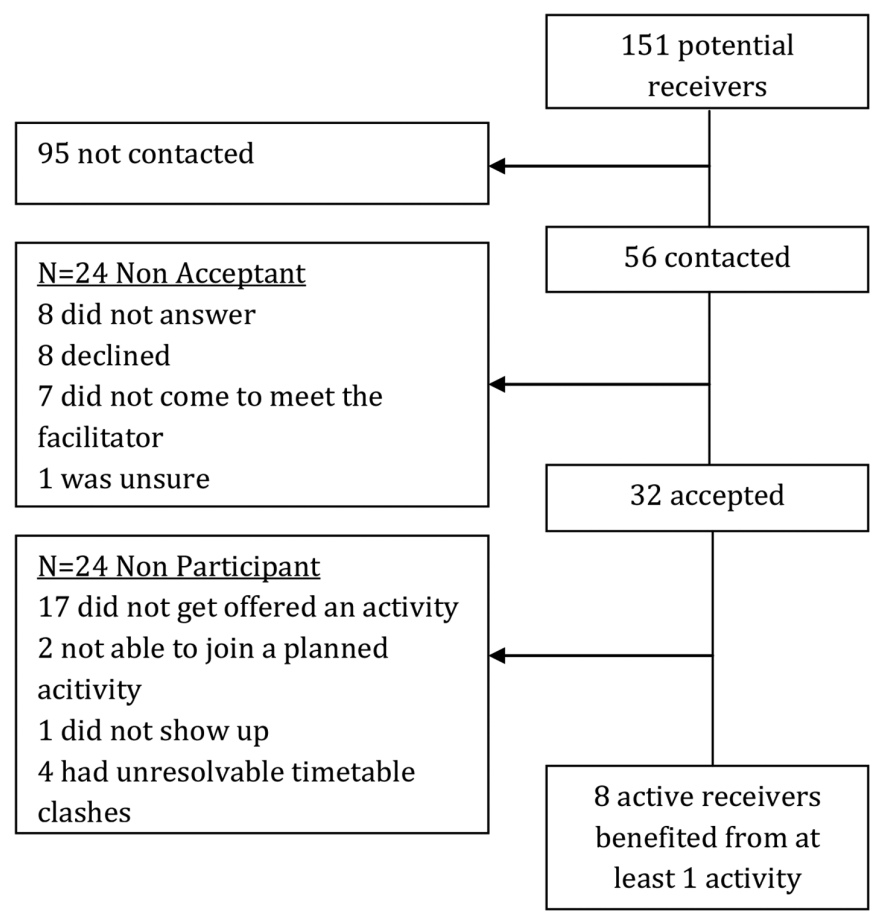

Figure 2 Interest and participation of the receivers. willingness to participate in a peer-led intervention had already been asked by a professional at the beginning of the year during the measurement and screening process. For the 45 potential receivers who gave an answer both to the professional and to the facilitator later on, there was a significant difference of acceptance of the peer intervention, with receivers more readily accepting when offered by a peer rather than a professional $\left(\mathrm{McNemar} \mathrm{X}^{2}=6.55\right.$; $51.2 \%$ discordant pairs; $p<0.02$ ). Of note is that of the 32 potential receivers who accepted the peer intervention, only 7 had declared lacking friends with whom to do physical activity on the IPAQ questionnaire.

\section{Characteristics of facilitators and receivers}

The characteristics of the 12 facilitators and 8 active receivers are described in table 1 . The individual characteristics of each facilitator and receiver are presented in online supplementary file 2. Of the 12 facilitators who continued after the training session, there were twice as many girls as boys. Facilitators were aged between 14 and 17 , with ambassadors naturally being older than the entrepreneurs on average since they belong to the year group above. The average age of active receivers is higher than the entrepreneurs, even though they came from the same year group. The BMI of the facilitators ranged from 20 to 29. Ambassadors who continued were mostly from professional high schools. Interestingly, entrepreneurs tended overall to have better health scores than the ambassadors and the receivers, which may be linked to the difference in BMI. The receivers who carried out 
Table 1 Characteristics of entrepreneurs, ambassadors and receivers

\begin{tabular}{|c|c|c|c|c|}
\hline & Entrepreneurs* & Ambassadors $†$ & Receivers & $\begin{array}{l}\text { Complete LASS } \\
\text { group }\end{array}$ \\
\hline$n$ & 7 & 5 & 8 & 262 \\
\hline \multicolumn{5}{|l|}{ Gender } \\
\hline Boy & 2 & 2 & 3 & 114 \\
\hline Girl & 5 & 3 & 5 & 148 \\
\hline \multicolumn{5}{|l|}{ School type } \\
\hline $\begin{array}{l}\text { General and technological high } \\
\text { school }\end{array}$ & 3 & 1 & 2 & 91 \\
\hline Vocational high school & 2 & 4 & 5 & 117 \\
\hline Middle school & 2 & 0 & 1 & 54 \\
\hline Age & 15.1 & 16.0 & 16.0 & 15.4 \\
\hline BMI & 22.3 & 27.0 & 28.8 & 26.8 \\
\hline FAS score & 4.0 & 4.6 & 4.3 & 4.1 \\
\hline EAT-26 score & 8.1 & 13.5 & 14.5 & 13.8 \\
\hline HAD score & 18.0 & 25.2 & 28.6 & 28.7 \\
\hline Anxiety score & 30.5 & 33.3 & 38.7 & 34.9 \\
\hline Depression score & 14.3 & 17.1 & 18.5 & 23.7 \\
\hline High & 3 & 0 & 2 & 61 \\
\hline Moderate & 1 & 2 & 6 & 96 \\
\hline \multicolumn{5}{|l|}{ Physical activity level } \\
\hline Low & 1 & 3 & 0 & 77 \\
\hline Missing & 2 & 0 & 0 & 28 \\
\hline Kidscreen score & 48.0 & 47.4 & 47.1 & 46.6 \\
\hline
\end{tabular}

*Data collected during the screening session at the start of the 2013-2014 academic year. †Data collected at the follow-up visit at the end of the 2012-2013 academic year.

BMI, body mass index; EAT-26; Eating Attitudes Test; FAS, Family Affluence Scale; HAD, Hospital Anxiety and Depression scale; LASS, less advantaged with standard and strengthened-care.

a weight-control activity seemed generally already quite active in their lives in terms of level of physical activity.

The 32 receivers who agreed to participate in the peer intervention had a higher BMI than the 25 who did not give a positive answer, and this result approached significance $(p=0.07)$. There were no other statistically significant differences between these two groups in terms of age, gender, school type, deprivation index, as well as anxiety, depression, bulimia or anorexia symptoms, physical activity, as well as perceived health and quality of life. The eight receivers having carried out an activity were significantly older ( 15.3 vs $16.1 ; \mathrm{p}=0.018$ ) than the 24 adolescents having said yes but who did not, for various reasons, participate in an activity. There was no significant difference between the adolescents who agreed to become facilitators and those who did not, both for entrepreneurs and ambassadors, on any of the above-mentioned variables.

\section{Weight-control activities and other tasks}

Several tasks were considered important in order to be a successful facilitator. Facilitators had to think of, plan and implement an activity without giving up during the school year. To be considered successful they also had to come to the training session, the mid-programme interview and the end-of-programme session. Of the 12 facilitators, 4 were considered to be very successful, having achieved all or the majority of the above-mentioned tasks.

It is clear that the task of implementing an activity was difficult for the facilitators as only half managed to do so, despite the vast majority having managed to think of and plan one. Furthermore, three facilitators formally quit before the end-of-programme session and one more tacitly quit by no longer answering any messages or calls.

In total, 12 weight-control activities were carried out by 6 facilitators (see table 2). Facilitators who did manage to plan and implement an activity then usually implemented two or more activities. Facilitators had a clear preference for organising activities centred on physical activity (10) rather than healthy eating (2), and they preferred organising activities during holidays or weekends, not on school days. Walking was a simple but popular activity among facilitators and receivers.

Although each facilitator was initially tasked with contacting several receivers and organising group 
Table 2 Weight-control activities carried out by the facilitators

\begin{tabular}{lllll}
\hline Day & Activity & Type & Receiver $^{*}$ & Facilitator $^{*}$ \\
\hline Weekday & Walking & Physical activity & R4b & F4 \\
Weekday & Cooking a meal & Healthy eating & R5a and R5b & F5 \\
Holidays & Walking & Physical activity & R6 & F6 \\
Holidays & Walking & Physical activity & R6 & F6 \\
Holidays & Walking & Physical activity & R6 & F6 \\
Holidays & Football & Physical activity & R1 & F1 \\
Holidays & Biking & Physical activity & R1 & F1 \\
Weekend & Walking & Physical activity & R4a & F4 \\
Weekend & Walking and Wii & Physical activity & R3 & F3 \\
Weekend & School meal & Healthy eating & R2 and friends & F2 \\
Weekend & Basketball & Physical activity & R1 & F1 \\
Weekend & Fitness trail & Physical activity & R3 & F3 \\
\hline
\end{tabular}

*Individual receivers and facilitators are anonymously numbered, with the number of the facilitators corresponding to the number of their matched receiver(s).

activities, in practice activities were carried out in dyads. Only two activities were carried out in a group, both for healthy eating activities. In fact, only one facilitator managed to organise activities with two different receivers. Furthermore, one facilitator was only able to carry out an activity by including her usual friends.

Although potential ambassadors were considerably more likely to agree to become a facilitator than potential entrepreneurs (see figure 1), entrepreneurs were much more likely to manage to organise and implement a weight-control activity with a receiver: five of the six who managed were entrepreneurs.

\section{Facilitator need for support}

The difficulty in organising weight-control activities for the facilitators is reflected in the acute need for support, which is highlighted by the high number of SMS exchanges and calls between the coordinator and the facilitators (table 3). The detail of the SMS exchanges and calls with each facilitator is presented in online supplementary file 3 .

The SMS exchanges and telephone calls show that intense support was necessary, whether or not the facilitators were more successful, and also whether or not they managed to implement an activity. The total number of SMS sent to the facilitators ranges from 24 to 180, with corresponding contact days between 12 and 67 . Between 4 and 15 telephone conversations on different days were also carried out with each facilitator.

In terms of the content of the SMS exchanges, activity feedback was the main purpose of the SMS exchanges, but this is closely followed by planning phone meetings for more indepth conversations. The most successful facilitators had a maximum of $20 \%$ missed calls, and for all but one, less than $10 \%$ no response rate to received SMS, suggesting that despite constraints, they were organised and reliable. A general observation can also be made in that the percentage of missed calls is much higher in general than the percentage of non-response to SMS contact, suggesting that adolescents prefer this mode of contact. The fact that entrepreneurs, much more often than ambassadors, successfully implemented activities is reflected by the higher number of contact days, total SMS exchanges and phone conversations.

Insights from interviews, focus groups and process data Facilitator views

The most illustrative quotes from the 6 training sessions, 11 mid-programme interviews, 4 end-of-programme

Table 3 Number and content of text message (SMS) exchanges and phone conversations between the coordinator and the facilitators

\begin{tabular}{lrr}
\hline & Entrepreneurs & Ambassadors \\
\hline SMS (mean) & & \\
\hline Plan training & 4.0 & 2.6 \\
\hline Plan call & 28.6 & 34.2 \\
\hline Plan interview & 5.4 & 6.0 \\
\hline Activity feedback & 33.3 & 7.8 \\
\hline Plan end session & 9.3 & 7.8 \\
\hline Total SMS sent & 105.4 & 81.6 \\
\hline Total received & 85.6 & 78.2 \\
\hline Number of contact & 43.3 & 37.4 \\
days & & \\
\hline \% no answer & 13.1 & 11.7 \\
\hline Call (mean) & & 7.8 \\
\hline Missed call & 7.3 & 7.2 \\
\hline Phone conversation & 10.6 & 31.8 \\
\hline \% missed & 30.0 & \\
\hline
\end{tabular}


sessions, telephone notes and SMS exchanges are presented in online supplementary file 4.

\section{Main challenges: organisational issues}

All facilitators encountered organisational issues, whether or not they managed to carry out an activity. However, each facilitator seemed to be faced with a different combination of challenges, indicating that none is in itself impossible to overcome. Major organisational issues, concerning 8 of the 12 facilitators or more, include lack of time, their own or that of their receivers, as well as timetable clashes, transport problems and remembering to carry out all the necessary tasks for organising the activity. These organisational issues were so common they were evidenced in all types of process data. An unforeseen major problem was the amount of time spent away doing internships for some students in professional high schools. Other common issues included having difficulties with the logistical organisation but also bad weather, which some facilitators considered problematic.

Furthermore, a very widespread but surprising difficulty, given it was specifically addressed during training, was the lack of ideas for what activities to organise. This was very present in the telephone notes as well as several SMS exchanges.

Another unexpected organisational difficulty was contacting the facilitators, even the very successful ones. Common issues were changing numbers and phones, but also having dysfunctional phones or sometimes not having a mobile phone for a certain amount of time before getting a new one. Several difficulties were also specific to working with less-advantaged adolescents, such as limited phone credit. The difficulty in contacting the facilitators is consistent with the high number of SMS sent to each facilitator (see table 3). These communication problems were also extremely frequent between the facilitators and the receivers. In fact, not having a mobile phone was often a reason for giving up on trying to organise an activity with a receiver. This happened to at least three facilitators.

\section{Increased need for support}

Related to the organisational issues mentioned above, a general finding is that even more support would be necessary to facilitate implementation at several levels of the peer intervention. Two facilitators expressed the need for help organising activities, even though one had managed to implement three activities. More specific help for the initial meeting with the receivers was also mentioned by four facilitators. This finding is consistent with the result that knowing the receivers to contact, at least by sight, greatly enhanced the success of facilitators. Indeed, knowing the receiver by sight was the case of all the facilitators having managed to implement an activity.

\section{Motivation issues}

The motivation of the facilitators fluctuated throughout the programme. Facilitators got frustrated when they were not able to organise an activity or when they felt that the receivers were not very motivated. The lack of motivation of the receivers manifested itself in several ways. Six facilitators experienced not receiving an answer from a receiver or a receiver not turning up to the planned activity, although the latter only happened once. Generally, all facilitators were confronted with some receivers not being very motivated and this was evidenced in all types of process data. For some receivers, the peer intervention was rejected because it belonged to the wider PRALIMAP-INES programme, which they had decided not to participate in.

\section{Programme clarity}

A main implementation point to improve is programme clarity in terms of the role of being a facilitator on the one hand and links with the broader PRALIMAP-INÈS programme on the other. For example, the selection of receivers was perceived as unclear, and nearly half of the facilitators spontaneously mentioned this lack of understanding at the end of the peer intervention despite it being mentioned during the training session. This reflects a gap in the perception of intervention necessity as acknowledged by a professional as opposed to the facilitators.

A related point of confusion is the link between the peer intervention and the wider PRALIMAP-INÈS programme. For example, several facilitators thought that through the peer intervention they would gain knowledge on diet and physical activity indirectly. Some also described the peer intervention as not really part of the wider programme, which was likely to be perceived as more formal since it was delivered by health professionals and with a clearer educational focus. Furthermore, several admitted that although they were happy being a facilitator, they would probably not have accepted being a receiver.

The training session purposefully did not provide information on diet and physical activity to facilitators as this information was imparted directly to participating adolescents, who were also the potential receivers, throughout the rest of the PRALIMAP-INÈS programme. Nevertheless, some facilitators took the initiative of talking about diet and physical activity with their receivers, and others on the contrary did not consider it to be part of their role. This point merits further specification during the training session.

\section{Health problems}

Another unexpected finding was the number of health problems experienced by the facilitators. All but two facilitators reported small health problems throughout the year, sometimes with the consequence of having to delay or replan an activity. For four facilitators, the health problems were significant enough to have to either completely give up their role as a facilitator or rule out a large range of activities. For example, tendinitis stopped one facilitator from doing any physical activity for several months, one potential facilitator did not continue after 
the training session since she had to undergo a double knee surgery, one facilitator had a severe epilepsy attack so was cautioned against physical activity, and one had to quit following an ice-skating accident.

\section{Interpersonal skills}

In terms of specific difficulties, it is clear that one facilitator in middle school had great difficulty with the role, not feeling comfortable especially in terms of social relations: she asked to change her receiver because she was afraid he had feelings for her and then asked to be able to carry out the activity with her own friends as well. In general, interpersonal skills were a common issue, and this finding suggests more specific training in interpersonal skills may be necessary.

Another unforeseen difficulty linked to the social context of the intervention was having several facilitators in the same school. This had initially been considered to be a motivating factor and was initially perceived as such by the facilitators concerned. However, in practice this complicated further the organisational task and actually delayed several activities being organised, which impacted the motivation of some facilitators.

\section{Good practice}

In general and in line with the implementation challenges identified above, supporting elements for successfully carrying out the role of facilitator, and evidenced principally in the telephone notes, were being proactive and having a lot of ideas, having free time and living close to the receivers.

Furthermore, several programme components seemed to facilitate implementation. In general, contact between the programme coordinator and the facilitators was perceived as very positive. Adolescents appreciated the procedure of first sending an SMS in order to agree on a time for a call, even though this was quite time-consuming (see table 3 ). The phone calls were very clearly experienced as motivating for all facilitators, whether they had been successful in their tasks or not. Overall, it can be stated that communicating via SMS is appreciated by adolescents, both with the coordinator and with the receivers. It is however important to acknowledge the fact that the adolescents, even the most reliable ones, can be unreachable for various reasons. It was therefore essential to have several means of contacting them. An additional possibility would be for the coordinator to contact the schools directly when there seems to be a communication problem.

When supportive of the programme, schools can be an important facilitating factor for implementation. For example, some schools successfully organised the meeting between facilitators and potential receivers, and one school nurse helped with selecting a receiver for a facilitator for whom previous contact with receivers had been unsuccessful.

A mixed finding was the support of parents. Although some facilitators seemed to share very little of their facilitator activities with their parents, despite sometimes being very successful, for others their parents were clearly very supportive, and for three facilitators parents had an active role in the implementation of the activities.

For ambassadors, a consistent finding is that they agreed to become facilitators because they liked participating in the PRALIMAP-INÈS programme the previous year. For all facilitators, it is clear that once they agreed to continue beyond the initial training session, they were motivated and committed to the PRALIMAP-INÈS programme in general, and they actively and informally promoted the programme to family, peers and friends, without this being specified in their role.

\section{Receiver views}

Of the six potential receivers interviewed, two had carried out an activity, one girl and one boy. Two girls can be considered passive receivers as they say they would have participated but do not remember being offered any activities by a facilitator, and two boys can be considered reluctant receivers as they clearly expressed their misgiving regarding the peer intervention. The most illustrative quotes from the different types of materials analysed are presented in online supplementary file 4.

\section{Social environment}

It can be noted that family problems were very frequently reported among the receivers and some seemed to have important household responsibilities. In terms of the broader environment in high school, views were mixed. Boys generally said they appreciated the school environment, especially those who were full boarders, but girls seemed less at ease. To a large extent, the appreciation of the school environment depended on the relationship with peers. For all adolescents, peers are important in order to laugh, talk and relax. However, a distinction is made about what is a real friend, which entails the crucial element of trust and being able to count on the person. What is very present in the description of friendship for all of the adolescents is the notion of proximity in terms of being in the same place and seeing each other frequently. This notion of proximity means that for the majority, they seem closer to their new friends in high school than their childhood friends. For some, age proximity is also important.

In terms of the number of friends, adolescent profiles were quite different. Two adolescents, a boy and a girl, were clearly very sociable and reported a large group of real friends. The others, including both active receivers, admitted having few close friends. Two reported just staying with a preferred best friend and the other two described a small group of two to four friends. For the majority, there seemed to be a general mistrust of peers and feelings of isolation. Some adolescents attributed their feeling of social exclusion to being overweight. 


\section{Health and overweight}

For the majority of adolescents, health was defined as the absence of disease, but also feeling in good shape. Public health norms of healthy eating and exercising were also understood and commonly mentioned. Interestingly, for two boys, health also included not being overweight.

For the majority of adolescents, being overweight was principally defined by referring to physical appearance and was directly linked to not feeling good about oneself. In fact, all but one adolescent interviewed expressed wanting to lose weight and reported attempts in that direction, even if this was mentioned indirectly.

However, many expressed that healthy behaviour was difficult, and this was particularly well illustrated by the fact that all adolescents but one reported that they frequently ate in a fast food restaurant. It is also apparent that what was particularly experienced as difficult was controlling what one eats. However, physical activity seemed to be something that was appreciated by the majority of adolescents.

\section{Programme experience}

The two adolescents who were active receivers were also those who enjoyed the wider PRALIMAP-INÈS programme. They found it fun and felt they were given good advice, and that it was helpful for behaviour change. The others went to at least one activity to try it but did not really understand the programme and found it uninteresting.

Similarly to the facilitators, there was an overall lack of clarity as regards the peer intervention. In fact, three receivers did not remember being contacted for a peer intervention. Interestingly, not knowing the facilitator in advance only seemed to be a problem for two of the adolescents interviewed, one of whom was actually an active receiver. It seems that the others would have been quite open to the peer activities had they understood what it entailed. Only one adolescent boy was firmly against the peer intervention but could not explain why.

The receivers who had benefited from a weight-control activity with a facilitator expressed enjoying the activities, especially the social component for the receiver who did not know the facilitator beforehand. In fact, it is interesting that the relationship continued beyond the peer intervention.

\section{DISCUSSION}

The intervention was implemented with a sufficient number of participants to provide recommendations as to the feasibility of the intervention in terms of demand, acceptability, implementation and practicality.

\section{Demand and acceptability}

A specific difficulty identified by a review of interventions for the prevention of obesity in adolescents was targeting interventions to a heterogeneous group, ${ }^{40}$ and it has previously been shown that although adolescents generally want to be more active, there is much intraindividual variation in what, where, when and with whom, suggesting that tailored activity promotion would be ideal. ${ }^{41}$ The wide range of profiles of the receivers in the present study is in line with this finding and highlights the potential advantage of implementing weight-control activities in peer dyads. Generally, although it can be said that the school setting allows all adolescents to be reached by health interventions equally, it is noteworthy that none of the peer weight-control activities were carried out in the school, and the results of the interviews with the receivers confirm that for many the school context is not favourable to feeling at ease given the general mistrust of peers. Indeed, the school setting can have a negative impact on the self-appraisal of overweight students through its normative structure, ${ }^{42}$ and conducting peer activities in a new environment may be more conducive to positive self-appraisal. This result suggests that health programmes taking place in the school setting could use a peer intervention component to reach adolescents who may not otherwise participate on the school premises. The opportunity of reaching otherwise hard-to-reach adolescents with a peer intervention is also supported by the finding that the receivers who accepted the peer intervention had a higher BMI on average than those who refused. Furthermore, all of the interviews carried out with receivers confirm that these adolescents wish to lose weight but find it difficult. It therefore seems that there is a real added value to peer interventions aimed at overweight adolescents of low SES.

The acceptance rate of the receivers seems sufficiently high to suggest satisfactory demand and acceptability of the programme, especially since they were more readily convinced to participate in the intervention when it was offered by a peer as opposed to a health professional. However, the acceptance rate and reach of the peer intervention could certainly be greatly improved in several ways. An unexpected finding was the widespread mistrust of peers in general. In fact, Puhl and colleagues ${ }^{43}$ found that, although peers were generally sought agents for support relative to parents, teachers or health professionals, they were also those who aroused most uncertainty, with nearly a quarter of adolescents unsure if they wanted their peers to intervene. Given the general mistrust of same-age peers of the receivers on the one hand, and the difficulty of the facilitators to contact the receivers on the other, a key improvement point would be for the coordinator to organise a joint meeting between the facilitators and receivers shortly after them having accepted the intervention. This would enable the dyad to get to know one another and would also be an opportunity to clarify what the peer intervention entails and the links with the broader health programme, and perhaps even plan together the first activity for the receiver and facilitator to carry out. Another improvement point which concerns both the receivers and facilitators is to multiply the contact modes available to reach them, ideally also liaising with the school for this to be possible. 
In their synthesis of reviews, Khambalia and colleagues ${ }^{1}$ recommend individualising interventions to particular student characteristics, particularly with regard to gender. Similar to other interventions, the present study had gender bias in terms of peer interveners. The difficulty in encouraging boys to volunteer has widely been acknowledged. ${ }^{6445}$ It is likely that a strategy solely based on altruistic volunteering is more appealing to girls considering the societal feminine-associated gender role of caregiving. ${ }^{46}$ Other strategies may be necessary to specifically motivate boys. One possibility would be to create a more competitive environment, such as is currently being developed in some peer interventions. ${ }^{41}$ It would also be important to conduct interviews with less-advantaged adolescent high school boys to understand which types of incentives are more engaging for this target group.

\section{Implementation and practicality}

The results of the present study point to several improvements that could enhance the feasibility of a peer intervention based on the implementation of weight-control activities among less-advantaged adolescents. In terms of the facilitators, contrary to expectations, it seems that entrepreneurs seem a better target than ambassadors. Indeed, although younger and less easily convinced to take on the role initially ( $69 \%$ refusal rate), they were by far the most successful facilitators. One reason could be that ambassadors have more academic pressure, being a year above and having national exams at the end of the year, which was not the case of the entrepreneurs. In France, students have national exams in 3ème (grade 9 ), the last year of middle school when adolescents are 14-15, but then also in the last 2 years of high school when adolescents are 16-18 (grades 11 and 12). An inherent problem with the school setting is that, although health topics and transferable skill development are considered important cross-curricular themes, health and education agendas are often in competition, with priority being given to core subjects. ${ }^{36478}$ A running question among peer education implemented in schools is the compatibility with students' school commitments, especially national exams. ${ }^{48}{ }^{49}$ Having less academic pressure may also explain the higher communicational activity of the entrepreneurs. Furthermore, the entrepreneurs seemed generally to be in better health, which is conducive to finding energy for the role of facilitator and being a positive role model.

The dose of support received by the facilitators throughout the school year seems appropriate from their point of view, but is time-consuming for the coordinator. This process could be improved since a very large portion of SMS exchanges were used for planning purposes, especially agreeing on a time to have more indepth discussions through phone calls. A more time-efficient strategy may therefore be to have a contact person in the schools, and a regular weekly or biweekly planned meeting according to the individual facilitators' timetables. In this scenario, SMS use would shift to a more supportive function: encouraging the facilitators, checking things are going as planned and prompts for the planned meetings. This would also counteract some of the contact issues (changing phone number, lack of credit, broken phone and so on).

The results of this study also suggest facilitators may need longer than a 2-hour training session, even if they are not expected to transmit information on diet and physical activity. The training session would particularly benefit from three additions. First, increased time spent clarifying the role of the facilitator and the link with the broader health programme seems necessary. Second, it seems important to give facilitators practical ideas based on the local facilities which should have been previously contacted so that the facilitators can reach a contact person for these activities if they are interested. Indeed, the result that walking was the most popular activity carried out is likely due to the fact that it was perceived as the simplest, not requiring any equipment whatsoever. Walking could therefore be considered the best practice activity to be suggested as the first to be carried out, to put facilitators and receivers at ease. However, it was clear from multiple exchanges with the facilitators that they would have happily engaged in many other types of activity had the opportunity arisen. Another possibility would be to create more supportive environments within the school setting, for example by making it easier for facilitators and receivers to make use of existing sports facilities, which often requires paperwork and adult supervision. This would require increased engagement from the school staff, which would have to be promoted prior to the start of the programme by involving key stakeholders in tailoring the peer intervention to the particular constraints of each school. Third, it may be important to provide specific training of interpersonal skills. The idea of providing more specific skills training for social support has been previously reported. ${ }^{20}$

The main improvement point is to facilitate the implementation of activities for the facilitators. Generally, our findings concur with the two main types of time constraints highlighted in other peer-led programmes: constraints linked to the implementation setting such as, for the school setting, exams or internships; and constraints linked to the peers themselves, such as family obligations, different timetables or residence location. ${ }^{6}$ Constraints due to the peers themselves may be even more significant when working with less-advantaged adolescents, as can be illustrated by the many family problems revealed during the interviews with receivers. Although there is evidence for an association between parental SES and adolescents' physical activity and dietary behaviours, ${ }^{50}{ }^{51}$ the many reported family problems make it unlikely that parental involvement would enhance the efficiency of the present intervention at the high school level.

It seems that the main logistical modification that can be made is to match facilitators and receivers based on place of residence. This is especially true since most activities were carried out outside of the school week. Although 
the school environment has many advantages, it has been noted that some facilities may not be readily available for weight-control activities, such as facilities for food preparation and consumption. ${ }^{52}$ This was also noted in the current study. The initial assumption that peer facilitators would be able to use school facilities was never put into practice. One main reason may explain this finding on top of the lack of facilities: the organisational burden in order to use the facilities. Another reason could be the strict health and safety regulations of the school setting. An additional advantage of implementing a peer intervention programme is the fact that if the adolescents live close enough, their activities can continue during the holidays. The summer holidays have been highlighted as a potentially important period of weight gain for adolescents, especially for overweight children and adolescents and ethnic minority groups. ${ }^{53}$

Another recommendation would be to encourage carrying out, at least at first, activities based on physical activity rather than healthy eating as this has the most potential to engage adolescents and activities in dyads rather than groups, since it is easier to organise. Although allowing people to be with their friends in order to engage in physical activity has been recognised as a key lever for behaviour change ${ }^{41}$ in practice it is difficult to create meaningful peer relations. In fact, although the peer-led activities were originally conceived as group activities, in practice peer interveners were only able to implement weight-control activities in pairs. This could be due to timetable clashes, but also perhaps the fact that with unfamiliar peers it is easier to gain each other's trust in pairs.

\section{Strengths and limitations}

Although some interventions have previously used peer education specifically to target disadvantaged children and adolescents, ${ }^{54}$ to our knowledge this is the first intervention purposefully to select peer facilitators based on SES. The peer intervention was embedded in a large-scale research study, which allowed systematic collection of data in all state-run high schools in the Vosges area in France, as well as some volunteer middle schools, totalling 33 schools. This allows conclusions to be drawn about selection procedures of facilitators and receivers, as well as the acceptability of the peer intervention. Furthermore, an indepth process analysis with different sources of qualitative materials was carried out to triangulate findings and inform practice as to the feasibility of the peer intervention. The limits of the present study relate to the small sample size of the facilitators and receivers. As a result, no statistical conclusions can be drawn with confidence as regards, first, the characteristics of the participants and, second, the impact of the peer intervention on the diet and physical activity behaviour of the receivers. However, the peer intervention was purposefully designed as a feasibility study given the innovative selection of facilitators. With a larger sample size, further research should aim to measure the health benefits to the receivers and the cost of the intervention. It would also be important to establish empirically the added value of selecting peer facilitators matched on receiver SES. Furthermore, the benefits of selecting less-advantaged facilitators should also be assessed as regards the potential empowerment of more vulnerable adolescents by encouraging them to take an active part in health programmes.

Acknowledgements Many people worked together to make a success of the PRALIMAP-INĖS trial and have been listed in the design, methods and rationale paper. We would like to express our gratitude to the participating students, parents and professionals in the participating schools.

Collaborators PRALIMAP-INÈS Trial Group: Philip Böhme (University Hospital of Nancy, Department of Diabetology, Metabolic Diseases and Nutrition, Nancy, France), Cécile Gailliard (National Conservatory of Arts and Crafts (CNAM), Nancy, France), Céline Pourcher (Academy Rector of Nancy and Metz, Nancy, France), Marie-Hélène Quinet (Academy Rector of Nancy and Metz, Nancy, France), Elisabeth Spitz (University of Lorraine, APEMAC EA4360, Metz, France) and Brigitte Toussaint (Academy Rector of Nancy and Metz, Nancy, France).

Contributors LS conceived and coordinated the intervention. SB, KL, JL, LM, AYO, RDL and EL participated in the intervention design and implementation. JK participated in the conception of the focus groups and interviews. LS and SR conducted focus groups and interviews, and LS conducted qualitative analyses. LS and SB conceived and drafted the manuscript with input from all members of the authorship team. SB coordinated the overall study. CA performed quantitative analyses. KL, CA, SR, JL, LM, AYO, RDL, JK and EL also reviewed the manuscript and contributed important intellectual content. All authors approved the final manuscript. Members of the PRALIMAP-INÈS (PI) contributed by giving feedback during intervention implementation.

Funding This work was supported by the French National Cancer Institute (INCA), a public institute, grant number 2011-239. The work of LS was supported by the University of Lorraine (PhD grant).

Competing interests None declared.

Patient consent Not required.

Ethics approval As an integral part of the PRALIMAP-INES trial (registered at ClinicalTrials.gov NCT01688453), ethics approval was obtained from the French consultative committee for treatment of information in health research (no 12.299), the French National Commission for Data Protection and Liberties (no 912372) and the French Persons Protection Committee (no 2012/15).

Provenance and peer review Not commissioned; externally peer reviewed. Data sharing statement № additional data are available.

Open access This is an open access article distributed in accordance with the Creative Commons Attribution Non Commercial (CC BY-NC 4.0) license, which permits others to distribute, remix, adapt, build upon this work non-commercially, and license their derivative works on different terms, provided the original work is properly cited and the use is non-commercial. See: http://creativecommons.org/ licenses/by-nc/4.0/

(C) Article author(s) (or their employer(s) unless otherwise stated in the text of the article) 2018. All rights reserved. No commercial use is permitted unless otherwise expressly granted.

\section{REFERENCES}

1. Khambalia AZ, Dickinson S, Hardy LL, et al. A synthesis of existing systematic reviews and meta-analyses of school-based behavioural interventions for controlling and preventing obesity. Obes Rev 2012;13:214-33.

2. Ayliffe B, Glanville NT. Achieving healthy body weight in teenagers: evidence-based practice guidelines for community nutrition interventions. Can J Diet Pract Res 2010;71:e78-86.

3. Langford R, Bonell $\mathrm{C}$, Jones $\mathrm{H}$, et al. The World Health Organization's Health Promoting Schools framework: a Cochrane systematic review and meta-analysis. BMC Public Health 2015;15:130.

4. Amini M, Djazayery A, Majdzadeh R, et al. Effect of School-based Interventions to Control Childhood Obesity: A Review of Reviews. Int J Prev Med 2015;6:68. 
5. Lee H, Harris KM, Lee J. Multiple levels of social disadvantage and links to obesity in adolescence and young adulthood. J Sch Health 2013;83:139-49.

6. Le Grand E. «ESPAIR » Rapport d'évaluation. Paris: Ministère des Sports, de la Jeunesse, de l'Education populaire et de la Vie associative Fonds d'Expérimentation pour la Jeunesse, 2012.

7. Roseman MG, Riddell MC, Haynes JN. A content analysis of kindergarten-12th grade school-based nutrition interventions: taking advantage of past learning. J Nutr Educ Behav 2011;43:2-18

8. Amsellem-Mainguy Y. Qu'entend-on par « éducation pour la santé par les pairs »? Cah L'action 2016:9-16.

9. Langlois J, Omorou AY, Vuillemin A, et al. Association of socioeconomic, school-related and family factors and physical activity and sedentary behaviour among adolescents: multileve analysis of the PRALIMAP trial inclusion data. BMC Public Health 2017;17:175.

10. Sawka KJ, McCormack GR, Nettel-Aguirre A, et al. Friendship networks and physical activity and sedentary behavior among youth: a systematized review. Int J Behav Nutr Phys Act 2013;10:130.

11. Salvy SJ, de la Haye K, Bowker JC, et al. Influence of peers and friends on children's and adolescents' eating and activity behaviors. Physiol Behav 2012;106:369-78.

12. Abdi F, Simbar M. The Peer Education Approach in AdolescentsNarrative Review Article. Iran J Public Health 2013;42:1200-6.

13. Azizi M, Hamzehgardeshi Z, Shahhosseini Z. Influential Factors for the Improvement of Peer Education in Adolescents: A Narrative Review. J Pediatr Rev 2017;5:e7692.

14. Villa-Torres L, Svanemyr J. Ensuring youth's right to participation and promotion of youth leadership in the development of sexual and reproductive health policies and programs. J Adolesc Health 2015;56:S51-7.

15. Ayaz S, Açıl D. Comparison of peer education and the classic training method for school aged children regarding smoking and its dangers. J Pediatr Nurs 2015;30:e3-e12.

16. Georgie J M, Sean H, Deborah M C, et al. Peer-led interventions to prevent tobacco, alcohol and/or drug use among young people aged 11-21 years: a systematic review and meta-analysis. Addiction 2016;111:391-407.

17. Cui Z, Shah S, Yan L, et al. Effect of a school-based peer education intervention on physical activity and sedentary behaviour in Chinese adolescents: a pilot study. BMJ Open 2012;2:e000721.

18. El Rayess F, Gandhi M, Mennillo H. Mark, Set, Go! School-Based Nutrition and Physical Activity Program: A Five-Year Evaluation. R I Med J 2017;100:39-44.

19. Sharif Ishak SI, Chin YS, Mohd Taib MN, et al. School-based intervention to prevent overweight and disordered eating in secondary school Malaysian adolescents: a study protocol. BMC Public Health 2016;16:1101.

20. Kulik NL, Fisher EB, Ward DS, et al. Peer support enhanced social support in adolescent females during weight loss. Am J Health Behav 2014;38:789-800.

21. Lloyd-Richardson EE, Jelalian E, Sato AF, et al. Two-year follow-up of an adolescent behavioral weight control intervention. Pediatrics 2012;130:e281-8.

22. McKinney C, Bishop V, Cabrera K, et al. NuFit: nutrition and fitness CBPR program evaluation. J Prev Interv Community 2014;42:112-24.

23. Santos RG, Durksen A, Rabbanni R, et al. Effectiveness of peerbased healthy living lesson plans on anthropometric measures and physical activity in elementary school students: a cluster randomized trial. JAMA Pediatr 2014:168:330-7.

24. Ladapo JA, Bogart LM, Klein DJ, et al. Cost and Cost-Effectiveness of Students for Nutrition and eXercise (SNaX). Acad Pediatr 2016;16:247-53.

25. Chandra-Mouli V, Lane C, Wong S. What Does Not Work in Adolescent Sexual and Reproductive Health: A Review of Evidence on Interventions Commonly Accepted as Best Practices. Glob Health Sci Pract 2015;3:333-40.

26. Harden A, Oakley A, Oliver S. Peer-delivered health promotion for young people: A systematic review of different study designs. Health Educ J 2001;60:339-53.

27. Bandura A. Social Foundations of Thought \& Action, a Socia Cognitive Theory. First Printing edition. Prentice Hall 1986.

28. Bagnall AM, South J, Hulme C, et al. A systematic review of the effectiveness and cost-effectiveness of peer education and peer support in prisons. BMC Public Health 2015;15:290.

29. Bowen DJ, Kreuter M, Spring B, et al. How we design feasibility studies. Am J Prev Med 2009;36:452-7.
30. Legrand K, Lecomte E, Langlois J, et al. Reducing social inequalities in access to overweight and obesity care management for adolescents: The PRALIMAP-INÈS trial protocol and inclusion data analysis. Contemp Clin Trials Commun 2017;7:141-57.

31. Cole TJ, Bellizzi MC, Flegal KM, et al. Establishing a standard definition for child overweight and obesity worldwide: international survey. BMJ 2000;320:1240-3.

32. McCarthy HD, Jarrett KV, Crawley HF. The development of waist circumference percentiles in British children aged 5.0-16.9 y. Eur J Clin Nutr 2001;55:902-7.

33. Currie CE, Elton RA, Todd J, et al. Indicators of socioeconomic status for adolescents: the WHO Health Behaviour in School-aged Children Survey. Health Educ Res 1997;12:385-97.

34. Boyce W, Torsheim T, Currie C, et al. The Family Affluence Scale as a Measure of National Wealth: Validation of an Adolescent Self-Report Measure. Soc Indic Res 2006;78:473-87.

35. Craig CL, Marshall AL, Sjöström M, et al. International physical activity questionnaire: 12 -country reliability and validity. Med Sci Sports Exerc 2003;35:1381-95.

36. Garner DM, Garfinkel PE. The Eating Attitudes Test: an index of the symptoms of anorexia nervosa. Psychol Med 1979;9:273-9.

37. Haines J, Ziyadeh NJ, Franko DL, et al. Screening high schoo students for eating disorders: validity of brief behavioral and attitudinal measures. J Sch Health 2011;81:530-5.

38. Zigmond AS, Snaith RP. The hospital anxiety and depression scale. Acta Psychiatr Scand 1983;67:361-70.

39. Ravens-Sieberer U, Erhart M, Rajmil L, et al. Reliability, construct and criterion validity of the KIDSCREEN-10 score: a short measure for children and adolescents' well-being and health-related quality of life. Quality of Life Research 2010;19:1487-500.

40. Doak CM, Visscher TL, Renders CM, et al. The prevention of overweight and obesity in children and adolescents: a review of interventions and programmes. Obes Rev 2006;7:111-36.

41. Corder K, Schiff A, Kesten JM, et al. Development of a universal approach to increase physical activity among adolescents: the GoActive intervention. BMJ Open 2015;5:e008610.

42. Crosnoe R, Muller C. Body mass index, academic achievement, and school context: examining the educational experiences of adolescents at risk of obesity. J Health Soc Behav 2004;45:393-407.

43. Puhl RM, Peterson JL, Luedicke J. Strategies to address weightbased victimization: youths' preferred support interventions from classmates, teachers, and parents. J Youth Adolesc 2013;42:315-27.

44. ÉL G. Professionnaliser les pairs-éducateurs est-il nécessaire ? Cah L'action 2016:75-82.

45. Strange V, Forrest S, Oakley A. Peer-led sex educationcharacteristics of peer educators and their perceptions of the impact on them of participation in a peer education programme. Health Educ Res 2002;17:327-38.

46. Karniol R. Gender Role Orientation, and Volunteering. Sex Roles 2003:49:11-19.

47. Langford $\mathrm{R}$, Bonell $\mathrm{C}$, Jones $\mathrm{H}$, et al. Obesity prevention and the Health promoting Schools framework: essential components and barriers to success. Int J Behav Nutr Phys Act 2015;12:15.

48. Audrey S, Holliday J, Campbell R. Commitment and compatibility: Teachers' perspectives on the implementation of an effective schoolbased, peer-led smoking intervention. Health Educ J 2008;67:74-90.

49. Corder K, Brown HE, Schiff A, et al. Feasibility study and pilot cluster-randomised controlled trial of the GoActive intervention aiming to promote physical activity among adolescents: outcomes and lessons learnt. BMJ Open 2016;6:e012335.

50. Finger JD, Mensink GB, Banzer W, et al. Physical activity, aerobic fitness and parental socio-economic position among adolescents: the German Health Interview and Examination Survey for Children and Adolescents 2003-2006 (KiGGS). Int J Behav Nutr Phys Act 2014;11:43.

51. Finger JD, Varnaccia G, Tylleskär T, et al. Dietary behaviour and parental socioeconomic position among adolescents: the German Health Interview and Examination Survey for Children and Adolescents 2003-2006 (KiGGS). BMC Public Health 2015;15:498.

52. Bell SL, Audrey S, Cooper AR, et al. Lessons from a peer-led obesity prevention programme in English schools. Health Promot Int 2017;32:dau008.

53. Franckle R, Adler R, Davison K. Accelerated weight gain among children during summer versus school year and related racial/ethnic disparities: a systematic review. Prev Chronic Dis 2014;11:E101.

54. Lubans DR, Morgan PJ, Aguiar EJ, et al. Randomized controlled trial of the Physical Activity Leaders (PALs) program for adolescent boys from disadvantaged secondary schools. Prev Med 2011;52:239-46. 